\title{
BiBLIOMETRY ABOUT FOREST FIRES
}

\section{O. A. Santana ${ }^{1}$}

${ }^{1}$ Universidade Federal de Pernambuco

\section{INTRODUCTION}

This research was motivated by the annual increase in forest fires worldwide [1]. The guiding question was 'Did the increase in the frequency of forest fires cause the scientific community to write more articles about this theme?' Thus, my hypothesis was 'the increased the number of publications about forest fires over the years was correlated with the increase in forest fires.' The objective was to analyze the evolution of scientific production about forest fires over the years (1900-2020).

\section{METHODOLOGY}

The used Keywords were "forest" and "fire" searched on Google Dataset Search [2]. The Filter was performed for filetype ("documents" and "texts"), license ("noncommercial use allowed"), subject ("Humanities"), and over the years: ("after:1900-01-01 before:1910-01-01"; "after:1910-01-02 before:1920-01-01"; "after:1920-01-02 before:1930-01-01"; "after:1930-01-02 before:1940-01-01"; "after:1940-01-02 before:1950-01-01"; "after:1950-01-02 before:1960-01-01"; "after:1960-01-02 before:1970-01-01"; "after:1970-01-02 before:1980-01-01"; "after:1980-01-02 before:1990-01-01"; "after:1990-01-02 before:2000-01-01"; "after:2000-01-02 before:2010-01-01"; "after:2010-01-02 before:2020-01-01").

The open collaboration for this research and workflow was published and shared in The Open Science Framework (Fig. 1).

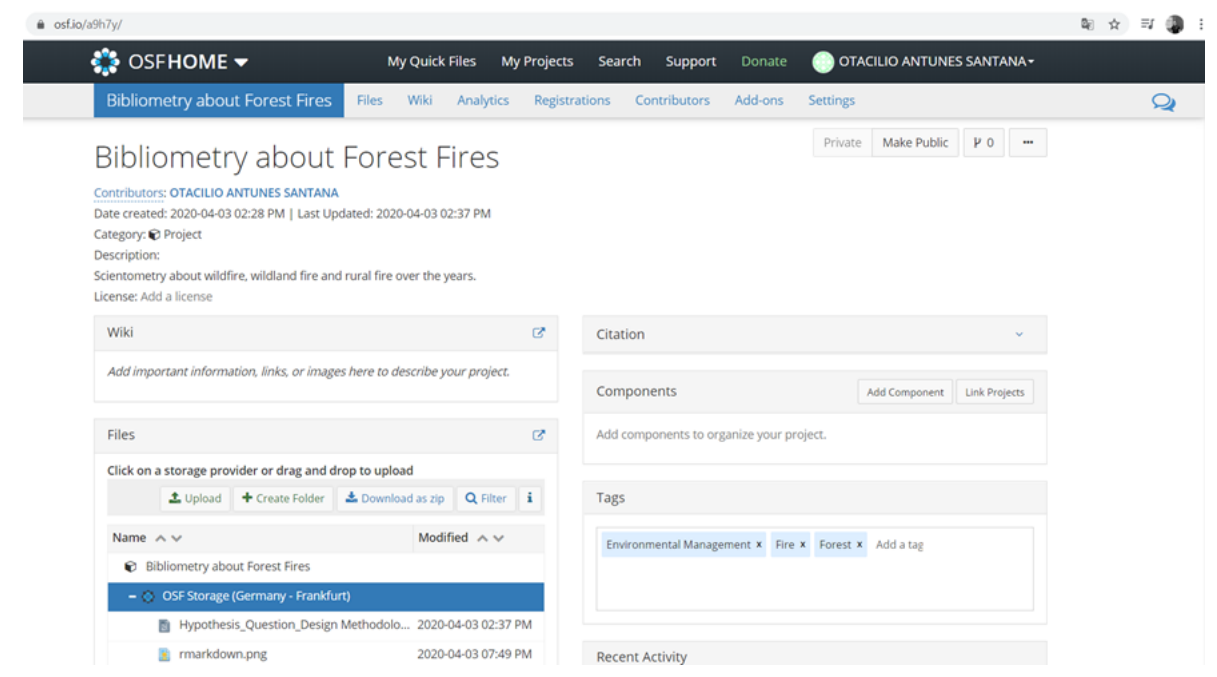

Fig. 1. The Project view in The Open Science Framework [3]. 


\section{RESULTS}

About $10^{9}$ documents and texts were found in search on Dataset (Fig. 2). The number of publications increased over the years and this data correlated proportionally with the number of register of forest fires, this last information was according with the literature [4].

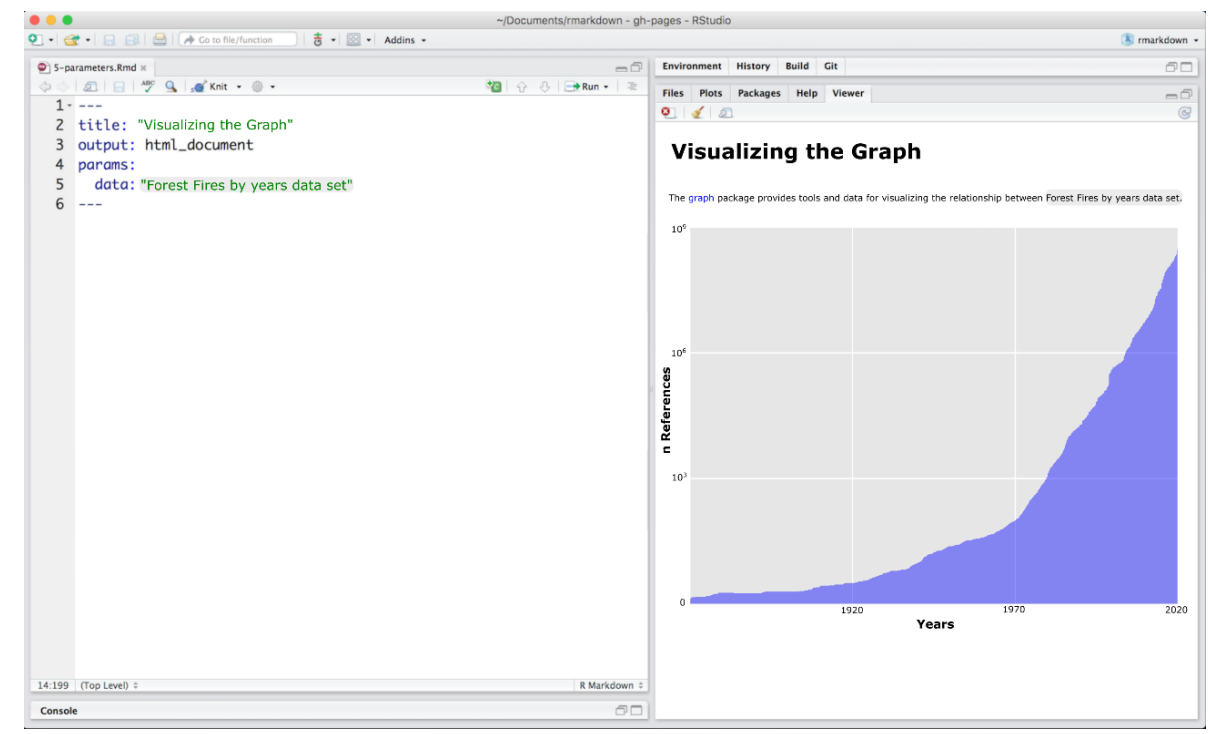

Fig. 2. Output of data in RMarkdown.

\section{CONCLUSION}

The hypothesis was accepted: the increased the number of publications about forest fires over the years was correlated with the increase in forest fires.

\section{REFERENCE}

[1] Boer, M.M., Resco de Dios, V. \& Bradstock, R.A. Unprecedented burn area of Australian mega forest fires. Nat. Clim. Chang. 10, 171-172 (2020). https://doi.org/10.1038/s41558-020-0716-1

[2] https://datasetsearch.research.google.com/

[3] https://osf.io/

[4] Aragão, L.E.O.C., Anderson, L.O., Fonseca, M.G. et al. 21st Century drought-related fires counteract the decline of Amazon deforestation carbon emissions. Nat Commun 9, 536 (2018). https://doi.org/10.1038/s41467-017-02771-y 